\title{
KONSEP WISATA BUDAYA KALIJA KELURAHAN TASIKMADU KECAMATAN LOWOKWARU KOTA MALANG
}

\author{
Mohammad Reza \\ Dosen Prodi Perencanaan Wilayah dan Kota, Fak. Teknik Sipil dan Perencanaan, \\ ITN Malang \\ e-mail: reza@ftsp.itn.ac.id \\ Endratno Budi Santosa \\ Dosen Prodi Perencanaan Wilayah dan Kota, Fak. Teknik Sipil dan Perencanaan, \\ ITN Malang \\ arsenal_end@yahoo.co.id \\ Titik Poerwati \\ Dosen Prodi Perencanaan Wilayah dan Kota, Fak. Teknik Sipil dan Perencanaan, \\ ITN Malang \\ e-mail: tpurwati@rocketmail.com
}

\begin{abstract}
ABSTRAK
Industri pariwisata pada umumnya memberi peran penting bagi perekonomian daerah karena dapat memberikan tambahan Pendapatan Asli Daerah sehingga penerimaan daerah meningkat, selain itu dapat menambah lapangan pekerjaan bagi masyarakat di sekitar tempat wisata, dimana potensi pariwisata tersebut dapat di kelola oleh penduduk setempat.

Tujuan dari penelitian ini yaitu untuk mengetahui konsep Wisata Budaya Kalija (Kalimantan Jawa) di Kelurahan Tasikmadu Kecamatan Lowokwaru Kota Malang. Metode analisa dalam penelitian ini menggunakan metode kualitatif dan berdasarkan kondisi eksisting dari lokasi penelitian. Wisata Kalija merupakan tempat wisata degan konsep budaya tradisional. Konsep wisata ini menyajikan objek wisata yang berbeda dibandingkan dengan objek-objek wisata lain yang ada di lingkup Malang Raya. Wisata Kalija akan menampilkan pentas budaya setiap harinya, secara bergantian antara Kalimantan dan Jawa. Wisata ini dibuat semenarik mungkin dan dapat membuat pengunjung merasa seakan berada di Kota Kalimantan maupun di Jawa.
\end{abstract}

\section{Kata kunci: Konep, Pariwisata, Budaya Kalija}

\begin{abstract}
In general, the tourism industry plays an important role for the regional economy because it can provide additional regional original income so that regional revenue increases, other than that it can increase employment for the community around tourist attractions tourism potential can be managed bylocal community. The purpose of this research was to determine the concept of Kalija Cultural Tourism (Kalimantan Kalimantan) in Tasikmadu Village, Lowokwaru District, Malang City. Method in this research uses a qualitative method and is based on the existing conditions of the research location. Results of this research: Kalija Tourism is a place of tourist with a traditional cultural concept. The concept of this tour presents a different tourist attraction compared to other attractions in the scope of Malang Raya. Kalija Tourism will showing cultural performances every day, alternately between Kalimantan and Java. This tour will
\end{abstract}

PAWON: Jurnal Arsitektur, Nomor 01 Volume IV, Bulan Januari-Juni Tahun 2020, ISSN 2597-7636 
maked very interesting and can make visitors feel comfortable in the city of Kalimantan and in Java.

Keywords : Concept, Tourim, Kalija Culture

\section{PENDAHULUAN}

Lahan pertanian merupakan salah satu sektor yang sangat penting dalam menyumbang pertumbuhan ekonomi di Indonesia. Alih fungsi lahan adalah penggunaan suatu lahan atau memfungsikan suatu lahan menjadi bentuk yang lain dari fungsi sebelumnya sesuai dengan kepentingan para pihak yang terlibat dalam alih fungsi tersebut. Alih fungsi lahan pertanian menjadi daerah pariwisata adalah memfungsikan suatu area pertanian menjadi daerah pariwisata. Setiap kegiatan alih fungsi lahan atau pemanfaatan lahan tidak bisa lepas dari aspek tata ruang. Setiap kegiatan alih fungsi lahan menjadi daerah pariwisata harus mengacu pada tata ruang daerah yang bersangkutan serta tidak merugikan kepentingan pihak lain. Dan juga setiap kegiatan alih fungsi lahan harus mengacu pada lingkungan hidup sehingga menjaga keseimbangan ekosistem dan pembangunan berkelanjutan.

Kelurahan Tasikmadu merupakan salah satu kelurahan di Kecamatan Lowokwaru Kota Malang yang memiliki lahan pertanian yang cukup luas. Beberapa wilayah di Kelurahan Tasikmadu memiliki penggunaan lahan yang didominasi berupa sawah, oleh karena itu sebagian masyarakat di Kelurahan Tasikmadu adalah petani.

Kegiatan pariwisata merupakan salah satu strategi yang dapat dikembangkan di lahan pertanian Kelurahan Tasikmadu Kecamatan Lowokwaru Kota Malang. Hal ini dapat menjadi upaya dalam meningkatkan Pendapatan Asli Daerah (PAD), dan memperluas lapangan usaha dan kesempatan kerja masyarakat yang ada di Kelurahan Tasikmadu. Dimana potensi pariwisata ini dapat di kelola oleh penduduk setempat dengan menggabungkan beberapa kebudayaan dari Indonesia.

Berdasarkan potensi dan masalah diatas, maka pada penelitian ini dapat dirumuskan permasalahannya yaitu: bagaimana membuat Konsep Wisata Budaya Kalija Kelurahan Tasikmadu Kecamatan Lowokwaru, Kota Malang.

\section{TINJAUAN PUSTAKA}

\subsection{Lahan Pertanian}

Lahan pertanian merupakan lahan yang diperuntukan untuk kegiatan pertanian. Sumberdaya lahan pertanian memiliki banyak manfaat

PAWON: Jurnal Arsitektur, Volume II Nomor 02, Juli-Desember 2018, ISSN 2597-7636 
bagi manusia. Menurut Sumaryanto dan Tahlim menyebutkan bahwa manfaat lahan pertanian dapat dibagi menjadi dua kategori. Pertama, use values atau nilai penggunaan dapat pula disebut sebagai personal use values. Manfaat inimengasilkan dari hasil eksploitasi atau kegiatan usahatani yang dilakukan pada sumber daya lahan pertanian. Kedua, non use values dapat pula disebut sebagai intrinsic values atau manfaat bawaan. Berbagai manfaat yang tercipta dengan sendirinya walaupun bukan merupakan tujuan dari kegiatan eksploitasi dari milik lahan pertanian termasuk dalam kategori ini.

\subsection{Alih Fungsi Lahan}

Alih fungsi lahan merupakan kegiatan perubahan penggunaan tanah dari suatu kegiatan yang menjadi kegiatan lainnya. Alih fungsi lahan muncul sebagai akibat dari pembangunan

Lahan selalu mengalami perubahan dari waktu ke waktu seiring meningkatnya kebutuhan manusia akan lahan. Perubahan tersebut dikarenakan memanfaatkan lahan untuk kepentingan hidup manusia. Alih fungsi lahan pertanian yang tidak terkendali apabila tidak ditanggulangi dapat mendatangkan permasalahan yang serius, antara lain dapat mengancam kapasitas lahan. Kecenderungan terus meningkatnya kebutuhan akan lahan ini menyebabkan alih fungsi lahan pertanian sulit untuk dihindari (lqbal, 2007).

\subsection{Pariwisata, Wisata Budaya dan Objek Wisata}

\subsubsection{Pariwisata}

Pariwisata adalah suatu sistem yang multikompleks dengan berbagai aspek yang saling terkait dan saling mempengaruhi antar sesama dan dalam beberapa dasawarsa terakhir. Pariwisata telah menjadi sumber penggerak dinamika masyarakat, dan menjadi salah satu prime-mover dalam perubahan sosial-budaya (Pitana dan Gayatri, 2007). Menurut Undang-undang Kepariwisataan Nomor 10 Tahun 2009 bahwa pariwisata merupakan berbagai macam kegiatan wisata dan didukung berbagai fasilitas serta layanan yang disediakan oleh masyarakat, pengusaha, pemerintah, dan pemerintah daerah. Kepariwisataan merupakan keseluruhan kegiatan yang berkaitan dengan pariwisata yang bersifat multidimensi dan multidisiplin yang muncul sebagai wujud kebutuhan setiap orangdan negara serta interaksi antara wisatawan dan masyarakat setempat,sesama wisatawan, pemerintah, pemerintah daerah, dan pengusaha.

\subsubsection{Wisata Budaya}

Sunaryo (2013: 26) menjelaskan bahwa pariwisata budaya adalah jenis obyek daya tarik wisata (ODTW) yang berbasis pada hasil karya cipta manusia baik yang berupa peninggalan budaya maupun nilai budaya yang masih hidup

PAWON: Jurnal Arsitektur, Nomor 01 Volume IV, Bulan Januari-Juni Tahun 2020, ISSN 2597-7636 
sampai sekarang. Pariwisata budaya ini perlu dikembangkan dengan tujuan untuk melestarikan kebudayaan itu sendiri agar tidak hilang seiring dengan perkembangan jaman (Wilopo dan Hakim, 2017:57).

\subsubsection{Objek Wisata}

Objek Wisata adalah adalah suatu perwujudan dari ciptaan manusia, tata hidupseni budaya serta sejarah bangsa dan tempat atau keadaan alam ciptaan tuhan yang mempunyai daya tarik yang dikunjungi wisatawan. Objek dan daya tarik wisata dapat digolongkan menjadi dua, yaitu benda atau objek peninggalan sejarah (heritage) dan seni budaya yang masih tetap hidup (living culture). Objek wisata budaya dapat berupa bangunan dengan arsitek khas atau peninggalan heritage sedangkan seni dan budaya berupa kesenian, sikap perilaku masyarakat atau adat istiadat (Fandeli, 2002). Menurut PP RI No. 67 Th. 1996 Objek wisata adalah sasaran wisata yang memiliki unsur fisik dominan, yang menarik untuk dikunjungi, ini berbeda dengan daya tarik wisata yang merupakan sasaran wisata yang memiliki unsur abstrak dominan, yang menarik untuk dikunjungi wisatawan.

\subsubsection{Daya Tarik}

Daya tarik wisata merupakan obyek atau atraksi wisata apa saja yang dapat ditawarkan kepada wisatawan mereka mau berkunjung ke hestanto.web.id suatu negara atau DTW (Daerah Tujuan Wisata) tertentu Yoeti (2008).

\section{METODE PENELITIAN}

\subsection{Lokasi Penelitian}

Lokasi penelitian berada di Kelurahan Tasikmadu Kecamatan Lowokwaru Kota Malang, dimana Kelurahan Tasikmadu yang terdiri dari 6 RW (Rukun Warga) dan 30 RT (Rukun Tetangga), sedangkan lingkup lokasi penelitian yaitu wilayah RT $04 \mathrm{RW} 03$.

\subsection{Pengumpulan Data}

Metode pengumpulan data yang digunakan yaitu melakukan dengan cara: Observasi (pengamatan) secara langsung dan wawancara, serta melakukan penelaahan kepustakaan dan survey instansi yang terkait.

\subsection{Metode Analisa}

Metode analisa dalam penelitian menggunakan metode kualitatif ini juga berdasarkan kondisi eksisting dari wilayah penelitian, misalnya konsep disain yang diinginkan oleh masyarakat, yang akan disesuaikan dengan kondisi di lapangan.

PAWON: Jurnal Arsitektur, Volume II Nomor 02, Juli-Desember 2018, ISSN 2597-7636 


\section{HASIL DAN PEMBAHASAN}

\subsection{Konsep Wisata Budaya Kalimantan Jawa (Kalija)}

Konsep perencanaan Kawasan wisata "Kalija" ini merupakan salah satu strategi yang dapat dikembangkan di lahan pertanian di RT 04 RW 03 di Kelurahan Tasikmadu. Hal ini dapat menjadi upaya dalam meningkatkan Pendapatan Asli Daerah (PAD),dan memperluas lapangan usaha dan kesempatan kerja masyarakat yang ada di RT 04 RW 03. Dimana potensi pariwisata ini dapat di kelola oleh penduduk setempat dengan menggabungkan beberapa kebudayaan dari Indonesia.

Salah satu tujuan dari konsep Wisata Kalija ini adalah memperkenalkan budaya khas asal Kalimantan dan Jawa. Dimana pengunjung akan menikmati permainan khas tradisional daerah tersebut dan juga dapat menyaksikan pentas kebudayaan yang telah disajikan di panggung budaya Kalija. Bangunan dan kawasan yang akan diangkat dalam konsep ini di buat sedemikian rupa menyerupai bangunan khas tradisional Jawa dan Kalimantan.

\subsection{Desain}

\section{Kawasan Wisata Budaya Kalija Berbentuk Burung Tingang}

Wisata Kalija sendiri di desain dengan berbentuk Burung Tingang yang merupakan hewan langka yang berasal dari Kalimantan. Pemilihan desain ini sengaja dibuat guna mengangkat budaya lokal khas Kalimantan yang merupakan dari bagian Tingang adalah sejenis burung yang mempunyai paruh berbentuk tanduk sapi tetapi tanpa lingkaran. Nama ilmiahnya "Buceros" merujuk pada bentuk paruh, dan memiliki arti "tanduk sapi". Dalam tradisi adat dan budaya Kalimantan, Burung Tingang (Tingang) merupakan simbol "Alam Atas" yaitu alam kedewataan yang bersifat "maskulin". Burung Tingang bisa dikatakan sebagai lambang kehidupan Suku Dayak. Hampir seluruh bagian tubuh Burung Tingang (bulu, kepala, paruh dll ) menjadi lambang dan simbol kebesaran Suku Dayak. Burung Tingang dijadikan sebagai lambang kebesaran, perdamaian dan persatuan; sehingga dalam kehidupan sehari-hari Burung Tingang senantiasa dipakai dalam bentuk patung, ukiran, lukisan, pakaian adat, rumah adat, balai desa, monumen, pintu-pintu gerbang, bahkan digunakan juga di pemakaman.

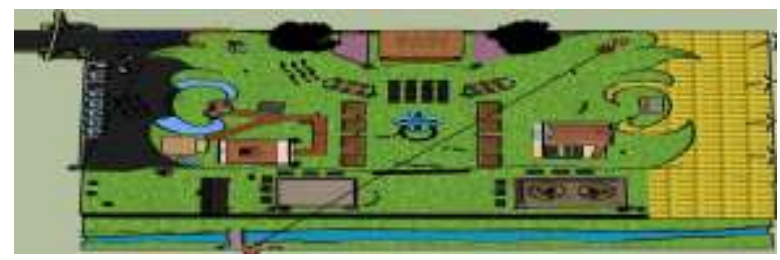

Gambar 1

Kawasan Wisata Kalija

PAWON: Jurnal Arsitektur, Nomor 01 Volume IV, Bulan Januari-Juni Tahun 2020, ISSN 2597-7636 


\section{Fasilitas Pendukung Kawasan Wisata Budaya Kalija}

\section{a. Gerbang Utama}

Gerbang Utama Wisata Kalija yang bertuliskan "Salamat Dumah Hong Kalija”. Kalimat tersebut di ambil dari bahasa Daerah Khas Dayak Ngaju Kalimantan Tengah yang berartikan selamat datang di Kalija. Kalimat ini dalam Khas Dayak mengandung arti bahwa kita menyambut seseorang dengan damai untuk masuk ke suatu tempat.

Gerbang utama Kalija di desain dengan berbentuk motif batik dari dua daerah yaitu Motif Batik Khas Kalimantan Tengah yang berada pada bagian atas gerbang dan Motif Batik Khas Malangan yang berada pada bagian bawah gerbang.

Perencanaan desain gerbang utama dengan motif batik ini ditujukan untuk menunjukkan karakteristik utama dari nama wisata "Kalija" sendiri yang berartikan Kalimantan Jawa.

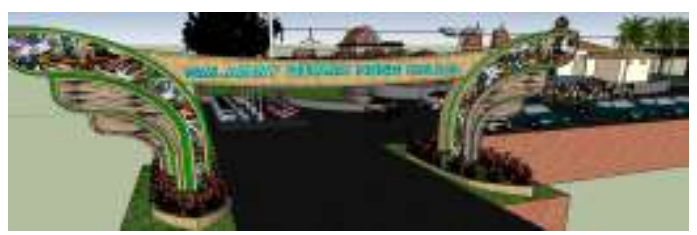

Gambar 2

Gerbang Utama Wisata Kalija

b. Tempat Parkir

Pada lokasi parkir Kalija, disediakannya parkiran motor dan parkiran mobil yang terletak di depan pintu masuk. Hal ini memudahkan pengunjung agar dapat memarkirkan kendaraannya langsung berdekatan dengan lokasi tujuan.

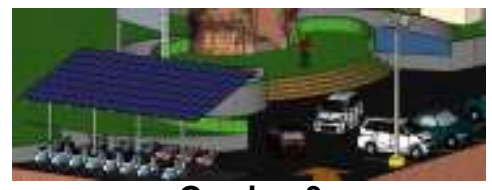

Gambar 3

Pakir Motor

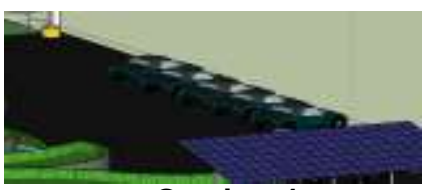

Gambar 4

Pakir Mobil

c. Pintu Masuk

Pintu masuk ini di desain dengan berbentuk Gapura Wringin Lawang yang berasal dari kebudayaan Jawa. Dimana Gapura tersebut memiliki beberapa makna yaitu :

- Gunung Mahameru. Gunung Mahameru ini diyakini sebagai persemayaman para dewa pada masa itu. 
- Gapura Wringin Lawang terbelah dua. Ini bisa diartikan sebagai konsep dualisme atau pasangan yang selalu ada di dunia, seperti kirikanan, atas-bawah, terang-gelap, laki-perempuan, dan masih banyak lagi yang lainnya. Bentuk terbelah ini ada juga yang menafsirkan dengan lambang kesuburan.

- Gapura Kecil yang menempel. Gapura kecil yang menempel ini bisa terlihat jika dilihat dari luar yang letaknya pada bagian induk. Gapura kecil ini digambarkan sebagai gerbang yang dimiliki rakyat dan yang lebih besar merupakan milik dari raja. Ini bisa diartikan sebagai kebijaksanaan raja lebih besar dari pada kekuasaan rakyat, namun rakyat sepenuhnya berada dibawah perlindungan kekuasaan dan kebijaksanaan raja.

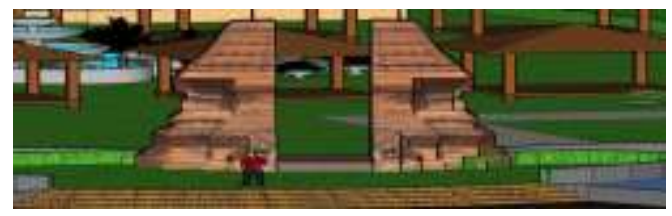

Gambar 5

Pintu Masuk Wisata Kalija

\section{d. Loket Karcis}

Perencanaan tempat loket karcis ini disediakan untuk membantu pengunjung dalam pembelian tiket masuk wisata Kalija. Bentuk karcis dibuat berupa gelang, oleh sebab itu karcis yang dijual adalah karcis yang sudah memuat seluruh permainan dan pementasan budaya serta fasilitas penunjang lainnya yang ada di Wisata Kalija, sehingga wisatawan yang sudah membeli karcis akan dapat mencoba semua permainan yang telah disediakan di Wisata Kalija.

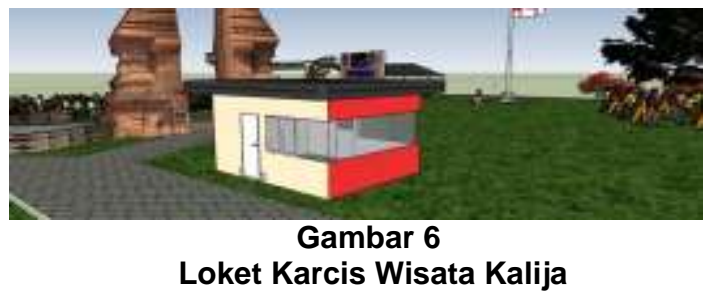

\section{e. Gazebo dan Air Mancur}

Penyediaan Gazebo ini berfungsi sebagai tempat pengunjung untuk dapat menikmati pemandangan alam. Bagian Tengah di gazebo diberi air mancur sebagai pemercantik pemandangan dan menimbulkan suara percikan air yang menggambarkan suasana alam terbuka.

Bentuk dari gazebo di Wisata Kalija sendiri berbentuk pendopo yang merupakan rumah daerah khas dari Pulau Jawa. Pendopo pada rumah Jawa terbuka tanpa pembatas pada keempat sisinya, hal ini

PAWON: Jurnal Arsitektur, Nomor 01 Volume IV, Bulan Januari-Juni Tahun 2020, ISSN 2597-7636 
melambangkan sikap keterbukaan pemilik rumah terhadap siapa saja yang datang.

Pendopo biasanya dibangun lebih tinggi dari halaman, ini dimaksudkan untuk memudahkan penghuni menerima tamu, bercakap-cakap sambil duduk bersila di lantai beralas tikar sesuai tradisi masyarakat Jawa yang mencerminkan suasana akrab dan rukun. Bentuk salah satu ruang dalam rumah tradisional Jawa tersebut memperlihatkan adanya konsep filosofis tentang makna ruang yang dalam di mana keberadaan pendopo sebagai perwujudan konsep kerukunan dalam gaya hidup masyarakat Jawa.

Pendopo tidak hanya sekadar sebuah tempat tetapi mempunyai makna filosofis yang lebih mendalam, yaitu sebagai tempat untuk mengaktualisasi suatu bentuk/konsep kerukunan antara penghuni dengan kerabat dan masyarakat sekitarnya. Pendopo merupakan aplikasi sebuah ruang publik dalam masyarakat Jawa.

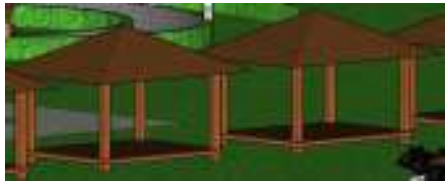

Gambar 7

Gazebo

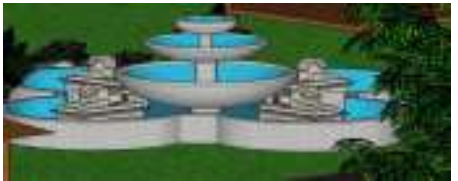

Gambar 8

Air Mancur

\section{f. Taman Berbentuk Talawang}

Taman di lokasi Wisata Kalija di desain dengan berbentuk Talawang. Tawalang sendiri merupakan senjata atau Perisai Khas Kalimantan Tengah yang memiliki arti sebagai pertahanan dalam berperang. Talawang sendiri berbentuk persegi panjang yang dibuat runcing pada bagian atas dan bawahnya. Sama halnya dengan Mandau, Talawang merupakan benda budaya yang lahir dari kepercayaan masyarakat Dayak terhadap kekuatan magis. Desain taman berbentuk Talawang ini dijadikan sebagai simbol sosial yang menggambarkan flora dan fauna. Ini menggambarkan bahwa kehidupan Masyarakat Dayak sangat penting untuk menjalin hubungan yang harmonis antara alam dan manusia.

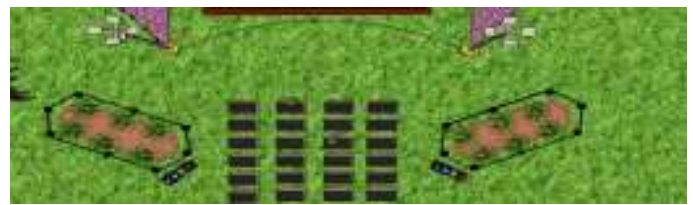

Gambar 9

Taman Berbentuk Talawang 


\section{g. Permainan Rubah Tarabang}

Rubah Tarabang adalah permainan asal Kalimantan, dimana Rubah Tarabang merupakan wahana yang cukup ekstrim, maka dari itu pengunjung harus memakai pengaman dan mengikuti instruksi dari petugas Kawasan Wisata Budaya Kalija, karena permainan ini dimainkan dari lokasi yang tinggi menuju lokasi yang rendah, dengan posisi pemain bergantung di atas tali.

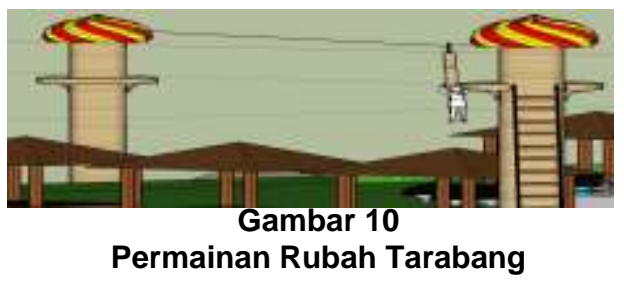

\section{h. Permainan Latupan Paring}

Latupan Paring merupakan salah satu permainan tradisional yang dimiliki oleh masyarakat khas Kalimantan. Permainan ini harus terus dijaga kelestariannya supaya tidak punah. Tradisi permainan Latupan Paring sudah mulai sulit ditemukan. Selain karena tergeser oleh berbagai macam jenis permainan modern juga karena sulit di dapatnya bahan-bahan untuk membuat meriam bambu yang berasal dari bahanbahan yang disediakan oleh alam.
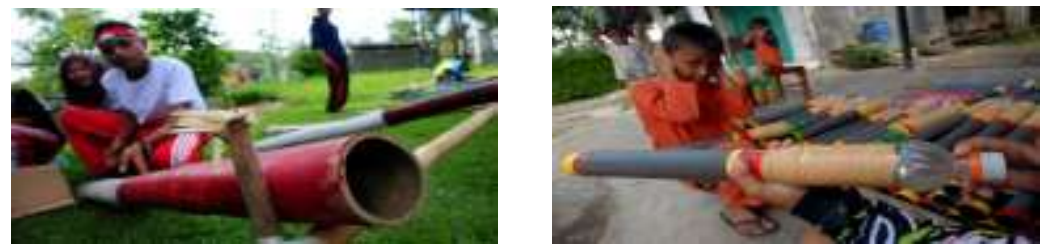

Gambar 11

Alat Permainan Latupan Paring

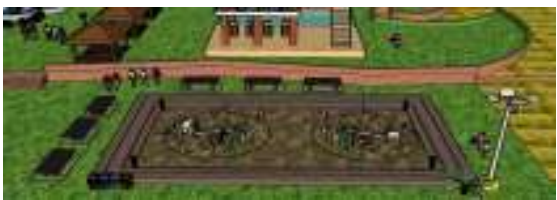

Gambar 12

Arena Permainan Latupan Paring

i. Pertunjukan Jaran Kepang

Jaran Kepang disebut juga Kuda Lumping adalah Tarian Tradisional Jawa yang menampilkan sekelompok prajurit tengah menunggang kuda. Tarian ini menggunakan kuda yang terbuat dari bambu atau

PAWON: Jurnal Arsitektur, Nomor 01 Volume IV, Bulan Januari-Juni Tahun 2020, ISSN 2597-7636 
bahan lainnya yang dianyam dan dipotong menyerupai bentuk kuda. Beberapa penampilan Jaran Kepang juga menyuguhkan atraksi kesurupan, kekebalan, dan kekuatan magis, seperti atraksi memakan beling dan kekebalan tubuh terhadap deraan pecut.

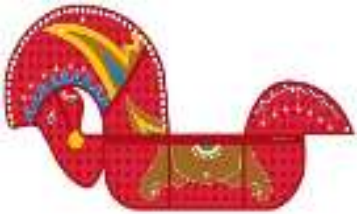

Gambar 13 Jaran Kepang

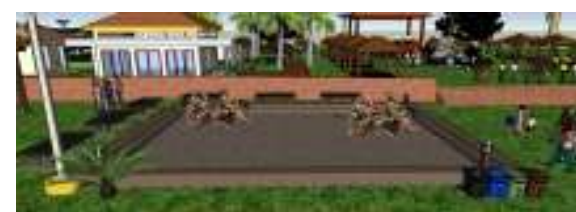

Gambar 14

Arena Permainan Jaran Kepang

j. Permainan Manyipet

Manyipet atau menyumpit sebuah alat khas merupakan sebuah khas asal Kalimantan Tengah yang pada zaman dahulu digunakan sebagai senjata dan alat untuk berburu. Pada zaman sekarang manyipet dijadikan sebagai olahraga tradisional yang di lombakan khususnya di Kalimantan Tengah yang di lombakan di event tahunan Isen Mulang.

Zaman dahulu, Anak Sumpit atau Damek adalah senjata yang berbahaya. Untuk efektivitas perburuan, masyarakat Dayak menggunakan racun di ujung damek. Racun itu berasal dari getah pohon Seraron. Pohon ini hanya ada di pedalaman hutan Kalimantan. Saking berbahayanya, jika terkena damek, tidak sampai 3 menit hewan buruan akan meregang nyawa. Racun ini hingga sekarang belum ditemukan penangkal racunnya. Pria dewasa suku Dayak jaman dulu, harus bisa menyumpit dengan tepat. Kepiawaian tersebut dijadikan penanda, seorang pria telat melewati fase remaja.

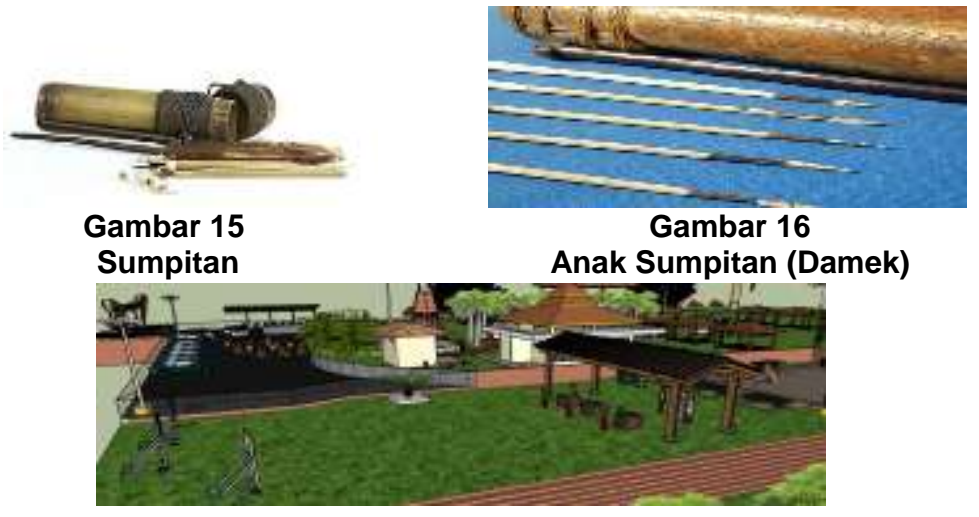

Gambar 17

Arena Permainan Manyipet

k. Rumah Makan Betang

PAWON: Jurnal Arsitektur, Volume II Nomor 02, Juli-Desember 2018, ISSN 2597-7636 
Rumah Makan Wisata Kalija di desain dengan bentuk Rumah Betang/Huma Betang yang merupakan rumah adat khas dari Kalimantan Tengah. Rumah Betang dibuat tinggi dengan maksud untuk menghindari dari banjir, serangan musuh, dan juga binatang buas. Lantai dan dindingnya terbuat dari kayu, sedangkan di bagian atap terbuat dari sirap. Adapun jenis-jenis makanan ciri khas daerah Kalimantan dan Jawa yang akan di sediakan dalam Rumah Betang.

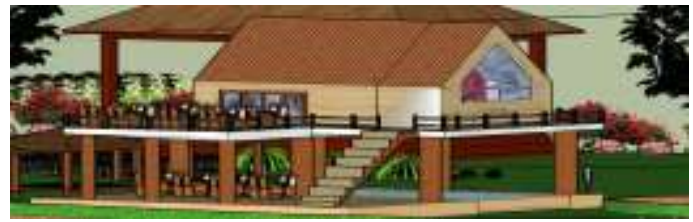

Gambar 18

Rumah Makan Betang

\section{Panggung Pentas}

Letak panggung pementasan utama ini berada arah Barat. Wisata Budaya Kalija menyediakan pertunjukan budaya dari 3 daerah yang berbeda yaitu Jawa, Kalimantan Selatan, dan Kalimantan Tengah. Untuk Pertunjukan Budaya yang ditawarkan dari Jawa ada Tari Topeng khas Malang dan Pertunjukan Wayang. Sedangkan dari Kalimantan Tengah menawarkan pementasan Tari Dadas dan Tari Manasai sedangkan dari Kalimantan Selatan menawarkan Tari Baksa Kambang dan pertunjukan teater Mamanda.

Desain dari panggung pementasan di Wisata Kalija ini sendiri berbentuk Rumah Joglo yang merupakan rumah adat atau bangunan arsitektur khas Jawa Tengah. Rumah Joglo mempunyai kerangka bangunan utama yang terdiri dari "Soko Guru" berupa empat tiang utama penyangga struktur bangunan serta tumpang sari yang berupa susunan balok yang disangga Soko Guru.

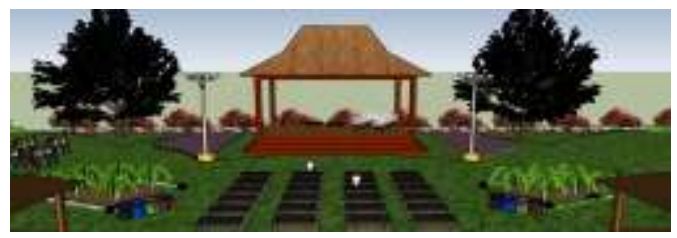

Gambar 19

Panggung Pentas

\section{KESIMPULAN}

Wisata Kalija merupakan tempat wisata degan konsep budaya tradisional. Nama Kalija sendiri merupakan singkatan dari Kalimantan dan Jawa. Sesuai dengan namanya, konsep dari wisata ini sendiri merupakan akulturasi dari budaya Kalimantan dan Jawa, sehingga di dalam lokasi wisata ini lebih mengusungkan budaya Kalimantan dan Jawa. Konsep wisata ini

PAWON: Jurnal Arsitektur, Nomor 01 Volume IV, Bulan Januari-Juni Tahun 2020, ISSN 2597-7636 
menyajikan objek wisata yang berbeda dibandingkan dengan objek-objek wisata lain yang ada di lingkup Malang Raya. Wisata Kalija akan menampilkan pentas budaya setiap harinya, secara bergantian antara Kalimantan dan Jawa.

Dilihat dari segi design pembangunan serta arena permainan tradisional yang ada. Wisata ini di bangun agar masyarakat atau wisatawan yang datang lebih mengenal budaya-budaya tradisional, khususnya budaya Kalimantan dan Jawa. Wisata ini dibuat semenarik mungkin dan dapat membuat pengunjung merasa seakan berada di Kota Kalimantan. Selain itu, pengunjung juga bisa dapat lebih mengenal permainan-permainan tradisional yang mungkin sudah dilupakan banyak generasi masa kini.

\section{DAFTAR PUSTAKA}

Arifin, Ir. T.M. Nur, M.Si, Elfiana, S.P.M.Si2017.. Dampak ahli fungsi lahan terhadap pendapatan petani di Kecamatan Jangka Kabupaten Bireuen. Jurnal S. Pertanian, Universitas Almuslim,vol. 1, No 12, 1104-1113.

Aryo Nugroho.W., Save to "Burung Tingang (Enggang)". http://kaderrakyat. blogspot.com/2013/03/save-to-burung-tingang-enggang.html

Fandeli Chafid. 2002., Perencanaan Kepariwisataan Alam. Yogyakarta: Fakultas Kehutanan Universitas Gadjah Mada.

Haryo Prasetyo dan Dr. Ing. Ir. Haryo Sulistiyarso. 2017. Arahan Pengembangan Kawasan Desa Wisata di Desa Tulung Rejo Kecamatan Pare Kabupaten Kediri. Jurnal Teknik ITS, Institut Teknologi Sepuluh November, Surabaya Vol 6. No 2, 2337-3520.

Helln Angga Devy, R.B. Soemanto. 2017. Pengembangan Obyek Dan Daya Tarik Wisata Alam Sebagai Daerah Tujuan Wisata Di Kabupaten Karanganyar. Jurnal Sosiologi DILEMA, Universitas Sebelas Maret, Surakarta Vol. 32, No. 1, 34-44.

Iqbal, N. 2007. Strategi Pengendalian Alih Fungsi Lahan Pertanian Bertumpu Pada Partisipasi Masyarakat. Pusat Analisis Sosial Ekonomi dan Kebijakan Pertanian. Bogor.

Pitana, I. Gede dan Gayatri, Putu G. 2005. Sosiologi Pariwisata. Yogyakarta: Andi,

Nyoman S. Pendit. 2006. IImu Pariwisata. PT Pradnya Paramita. Jakarta.

Sumaryanto, Tahlim S. 2005. Pemahaman Dampak Negatif Konversi Lahan

Sawah Sebagai Landasan Perumusan Strategi Pengendaliannya.

Prosiding seminar penanganan konversi lahan dan pencapaian pertanian abadi. Satyawan Et al. Pusat studi Pembangunan Pertanian dan Pedesaan LPPM-Institut Pertanian Bogor.

Sunaryo, Bambang. 2013. Kebijakan Pembangunan Destinasi Pariwisata

Konsep dan Aplikasinya di Indonesia. Yogyakarta : Gava Media.

Suwantoro, Gamal. 2004. Dasar-dasar Pariwisata. Yogyakarta: Andi Offset.

PAWON: Jurnal Arsitektur, Volume II Nomor 02, Juli-Desember 2018, ISSN 2597-7636 
Undang-undang Republik Indonesia No.10 Tahun 2009 tentang Kepariwisataan

Wilopo,K.K dan Hakim, Luchman. Strategi Pengembangan Destinasi Pariwisata Budaya.Vol. 41 No.1 Januari 2017 
